\title{
An implementation of new dynamic site index models in a company's timber supply analysis
}

\author{
by C.J. Cieszewski ${ }^{1}$, I.E. Bella ${ }^{2}$ and D. Walker ${ }^{3}$
}

\section{Introduction}

Forecasting stand volume growth and yield is critical to timber supply analysis. Stand height growth is an important component of these forecasts. More directly, differences among stands in rate of height growth provide foresters with a useful measure for rating relative site productivity, through height measurements and site index (SI).

This note documents implementation of a new dynamic height growth model within an industrial timber supply analysis. The new model was developed by the Canadian Forest Service (CFS) with support and cooperation from Alberta Lands and Forests Services (ALFS) and Weldwood Canada Ltd. (Hinton Division). This note summarizes development of a model and its implementation by Weldwood in its timber supply analysis.

\section{Model Description}

Site index, along with species mix and crown closure, is used by Weldwood to sort stands into productivity classes for timber supply analysis. Traditionally, SI refers to a height at a fixed age, usually 50 years in this region. Generally, SIs are not available for most stands. Forests are composed of stands at various ages, and site indexes are determined through the use of available growth models available tree heights at these ages. When one wants to estimate height at a particular age, one first needs to estimate SI from a current height and age. Prior to 1989, height growth models used by Weldwood were based on the static fixed base age model described in (Alberta Dept. Energy and Nat. Res. 1985), which was unsolvable for SI. To estimate SI from height and age measurements (at any breast height age other then 50 years), foresters had to use either separate equations developed from linear regression analysis and estimate SIs from heights and ages; or approximate them iteratively using suitable computer programs. Drawbacks of separate equations for SI estimation were:

- SI had a fixed base - age which had to be estimated separately;

- SI equations were not compatible with corresponding height equations; and

- accurate and consistent estimates of SIs required iterative numerical approximations.

In 1989, CFS derived a new dynamic height/SI model for lodgepole pine (Pinus contorta Dougl. var. latifolia Engelm.), as part of an effort to develop a managed stand growth and yield model for this species (Cieszewski and Bella 1989). The

\footnotetext{
${ }^{1}$ Formerly Research Scientist, Forest Mensuration, Natural Resources, Canadian Forestry Service, Northern Forestry Center, Edmonton, AB. Now Assistant Professor, Fiber Supply Assessment, School of Forest Resources, University of Georgia, Athens, GA, USA.

${ }^{2}$ Formerly Project Leader, Stand Productivity, Natural Resources, Canadian Forestry Service, Northern Forestry Center, Edmonton, AB. Now retired. ${ }^{3}$ Formerly with Weldwood of Canada Limited (Hinton, Division), while this project was completed. Now at Timberline Forest Inventory Consultants, \#315 10357-109 St., Edmonton, Alberta, T5J 1N3.
}

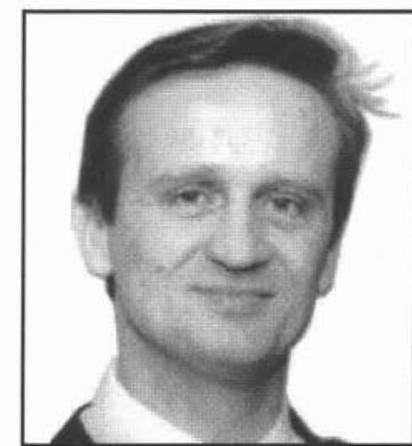

C.J. Cieszewski

new model was derived through formulation of biological theories describing the height growth processes of lodgepole pine. It was calibrated on stem analysis data provided by ALFS and it constituted the first truly base-age invariant (Bailey and Clutter 1974), polymorphic (i.e., curve shapes that varied with SI) equation with variable asymptotes (asymptotes are different on various site productivity) that computes biologically sound predictions throughout all applicable range of ages. The dynamic model used only two estimable coefficients (three were available) to predict the height growth or yield at any age directly from any other height and age, rather than through the intermediate estimation of the traditional fixed age SI. Thus, a single initial condition difference equation could provide both height growth and SI estimates that were compatible with each other. In addition to the above, the new model computed curve trends originated in zero, increased asymptotes with increasing site productivity, and height at age 50 equal SI.

Because the new model is capable of predicting height directly from a height at any age (any such height may be regarded as SI of a different base age), it was named a variable-ageSI (VASI) height growth model. In this context, the term height was given two meanings:

1. a computed height $H\left(t, h_{x} x\right)$ for an age of prediction ( $\left.t\right)$, and 2. a known height $(h)$ at any other age $(x)$, used in conjunction with its age $(x)$ as a reference point instead of the SI (if $x=50$ then $h_{x}$ is equivalent to SI).

The new dynamic site equations had the following form:

$$
H\left(t, h_{x}, x\right)=\frac{h_{x}+b 50^{a}+\sqrt{\left(h_{x}-b 50^{a}\right)^{2}+4 b h_{x} x^{a}}}{2+4 b t^{a} /\left[h_{x}-b 50^{a}+\sqrt{\left(h_{x}-b 50^{a}\right)^{2}+4 b h_{x} x^{a}}\right]}
$$

where $a$ and $b$ are model coefficients and the derivation con- 


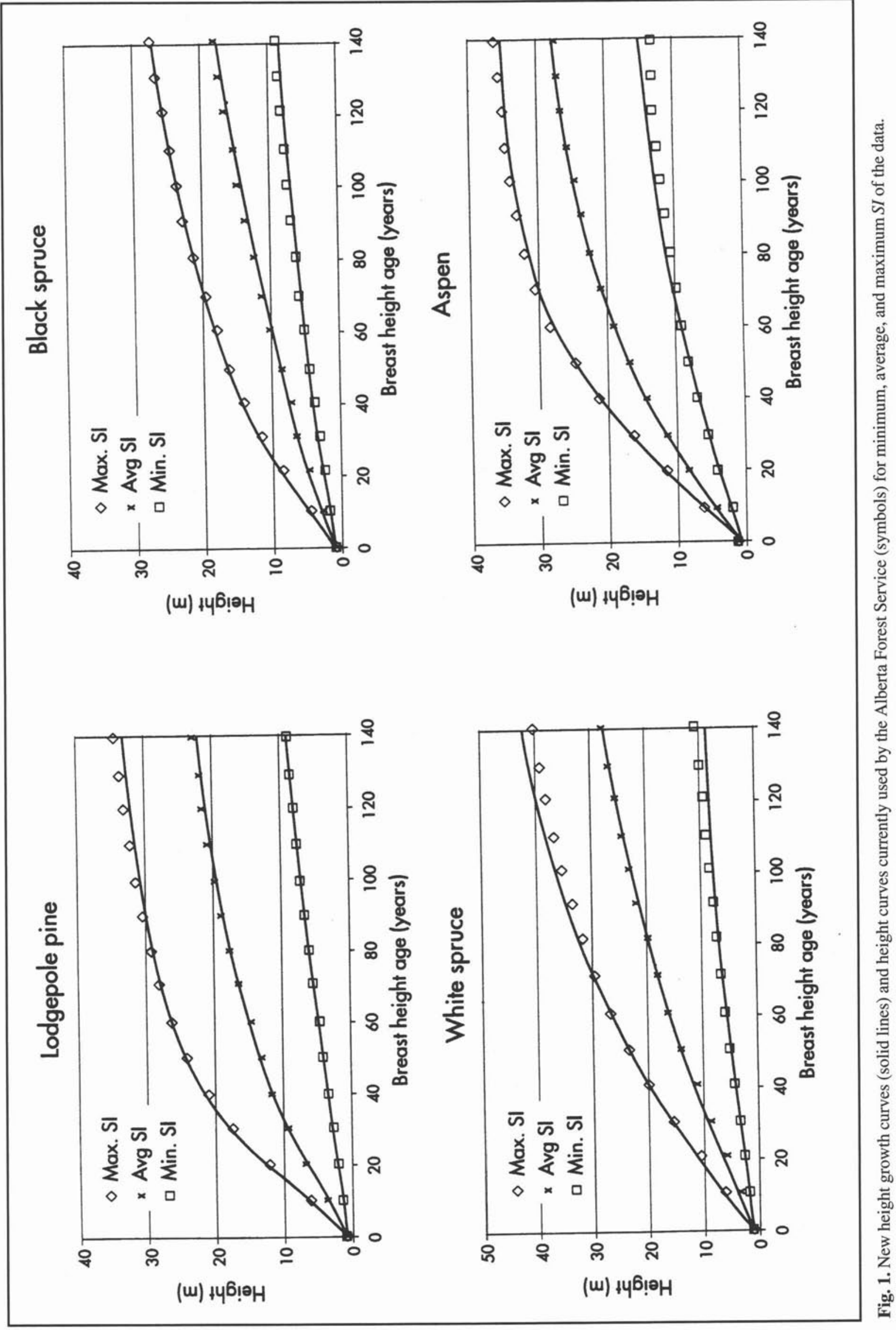


stant 50 can be readily replaced by a third coefficient. The model coefficients for all species were determined by non-linear regressions using stem analysis data (Cieszewski and Bella 1991).

Following the development of this model, the CFS approached the ALFS and members of the forest industry in Alberta, to coordinate a joint effort to pool data from different sources and calibrate the same model for all major commercial timber species in the province. Positive responses came from ALFS and Weldwood Canada in Hinton. Weldwood offered access to their stem analysis data in return for an exclusive calibration of the new dynamic height growth model for their FMA area. The corporate data and the model calibrated on this data could not be published, but the Weldwood data were used to strengthen the overall database. The lodgepole pine VASI height growth model was calibrated on all the pooled data (Cieszewski and Bella 1991). The ALFS and CFS pooled data were also used for calibration of the model for other major commercial tree species in Alberta, i.e., for white spruce (Picea glauca (Moench) Voss), black spruce (Piceamariana (Mill.) B.S.P.), and trembling aspen (Populustremuloides Michx.).

\section{Model Calibration}

Data used for calibration of the new model were from stem analysis of dominant and codominant trees collected by the ALFS, CFS, and Weldwood. The sample covered each species' commercial range in Alberta. Trees were felled, the total height was measured, and sections for ring (age) counts were obtained at stump, breast height (bh), and in fixed intervals between 1.0 to $2.5 \mathrm{~m}$ lengths above breast height.

Initial data screening for all sample trees was based on the following criteria:

1. non-decreasing ages with increasing heights;

2. minimum of three acceptable measurements above bh per tree; and

3. minimum bh age of 50 years at the time of felling.

These constraints eliminated up to $651 \%$ of the trees.

In the next step, individual tree data were plotted and screened for suppressed early growth and top damage. From the data that passed all these selection criteria, decadal values of height growth (i.e., heights at ages 10, 20, 30, etc. years) were interpolated and used in the subsequent analyses.

Equation 1 was fitted on all decadal height values using nonlinear least-square regressions. All regression fittings were initially performed with customized Simplex software ${ }^{4}$. These regression analyses were rerun using SAS to obtain additional statistics. Regression coefficients, their standard errors and tstatistics, as well as standard errors of height predictions, residual variation coefficients $\left(R V C=\frac{S E}{M e a n H t}\right)$ and R-squares for each species are given in Cieszewski and Bella (1991).

The new height growth curves generated by Equation 1 for lodgepole pine, white spruce, black spruce, and aspen are shown in Fig. 1. For comparison, Fig. 1 also includes point estimates in 10-year steps of height growth curves previously used by the ALFS (Alberta Dept. Energy and Nat. Res. 1985).
To sum up, the new height/SI model provides curves that are similar in shape to those previously used in Alberta, with some differences in the extremes of site indexes and ages. The main advantages of the new model are compatibility of height and SI predictions, and that it can predict height directly from a height at any age without first estimating site index. Therefore, it can be used both as a height growth model and a site index model. Use of the new model is facilitated with a FORTRAN program (Cieszewski and Bella 1991).

\section{Model Application}

The VASI model was used to predict SI for fire-origin stands where the primary species was lodgepole pine, trembling aspen, or black spruce. The predicted SI values were assumed to represent stand SI. The VASI model consistently underestimated white spruce SI, because of high stand ages, white spruce seed periodicity, and uneven growth habits. Therefore, original SI curves were retained for this one species.

The VASI model was not used for predicting SI in regenerated stands, because of the variability evident in early stand growth. Site indexes for regenerated lodgepole pine were estimated using separate growth intercept method. Site indexes for other regenerated types were estimated from historic averages.

Weldwood's consultants (W.R. Dempster and Associates Ltd., a Division of H.A. Simons Ltd.) implemented the VASI model within the process they used for Weldwood in assigning SI values to stands. After SIs were assigned to all stands, these were used to access height-volume tables, producing a set of volume-age tables for timber supply analysis (W.R. Dempster and Associates 1991). Upon providing these tables to Weldwood, timber supply analysis was completed in-house.

\section{Acknowledgements}

Development of the VASI model was supported in part by the Canada-Alberta Forest Resource Development Agreement. Stem analysis data came from Alberta Lands and Forests Services, Canadian Forest Service, and Weldwood of Canada Ltd. (Hinton Division).

Weldwood staff members Sean Curry and Bob Udell participated, along with Doug Walker, in the decision to use the VASI model. Neil Stevens of W.R. Dempster and Associates supervised actual implementation and use of the VASI model.

\section{References}

Aberta Dep. Energy and Nat. Res. 1985. Alberta Phase 3 Forest Inventory: Yield Tables for Unmanaged Stands. Rep. 60.

Bailey, R.L. and J.L. Clutter. 1974. Base-age Invariant Polymorphic Site Curves. For. Sci. 20: 155-159.

Cieszewski C. J. and Bella I.E. 1989. Polymorphic height and site index curves for lodgepole pine in Alberta. Can. J. For. Res. 19: 1151-1160.

Cieszewski C. J. and Bella I.E. 1991. Polymorphic height and site index curves for the major tree species in Alberta. FMN 51.

W.R. Dempster and Associates Ltd. 1991. Aerial stand volume tables and volume age areas for Weldwood of Canada Ltd., Hinton Division. Volume 1. Report and tables. W.R. Dempster and Associates Ltd., Edmonton, AB. 12 p. plus app. 